\title{
Protection against COVID-19 in African population: Immunology, genetics, and malaria clues for therapeutic targets
}

\author{
Marcos Altable
}

Funding: The author(s) received no specific funding for this work.

Potential competing interests: The author(s) declared that no potential competing interests exist.

\section{Abstract}

Background: There is a marked discrepancy between SARS-CoV-2 seroprevalence and COVID-19 cases and deaths in Africa.

Main: SARS-CoV-2 stimulates humoral and cellular immunity systems, as well as mitogen-activated protein kinase (MAPK) and nuclear NF-kB signalling pathways, which regulate inflammatory gene expression and immune cell differentiation. The result is pro-inflammatory cytokines release, hyperinflammatory condition, and cytokine storm, which provoke severe lung alterations that can lead to multi-organ failure in COVID-19. Multiple genetic and immunologic factors may contribute to the severity of COVID-19 in African individuals when compared to the rest of the global population. In this article, the role of malaria, NF-kB and MAPK pathways, caspase-12 expression, high level of LAIR-1containing antibodies, and differential glycophorins (GYPA/B) expression in COVID-19 are discussed.

Conclusion: Understanding pathophysiological mechanisms can help identify target points for drugs and vaccines development against COVID-19. To our knowledge, this is the first study that explores this link and proposes a biological and molecular answer to the epidemiologic discrepancy in COVID-19 in Africa.

\section{Background}

The novel coronavirus disease (COVID-19) is caused by severe acute respiratory syndrome (SARS) coronavirus 2 (SARS-CoV-2), which rapidly spread globally [1]. As of 21 August 2020, there have been 22,536,278 confirmed cases of COVID-19, including 789,197 deaths, reported to WHO [2]. The disease has a mortality rate of $3.5 \%$ although this widely varies across different countries. African mortality from COVID-19 is 1.7\%, almost half of the global mortality (3.3\%) and three-fold lower than European mortality (5.7\%). Uyoga et al. recently reported the seroprevalence of anti-SARS-CoV-2 IgG antibodies in Kenyan blood donors. This study was the first national and regional estimation of population exposure to SARS-CoV-2 in an African country. Results showed that three urban counties, namely Mombasa, Nairobi, and Kisumu, had the highest prevalence, with $9.3 \%, 8.5 \%$, and $6.5 \%$ respectively, which sharply contrast with the minimal number of COVID-19 cases and deaths reported during the same period. The crude prevalence was 5.6\%, while the populationweighted, test-adjusted seroprevalence was $5.2 \%$. The cause of this discrepancy is currently unknown [3]. 
Various investigations have discussed the vulnerability of African populations to the expansion and higher incidence of COVID-19 since the continent has experienced endemic diseases, such as tuberculosis, human immunodeficiency virus, and malaria in recent decades, in addition to emerging and re-emerging infectious pathogens, such as Lassa haemorrhagic fever or Ebola virus disease [4]. One factor that facilitates the rapid spread of diseases in Africa is population density [5]. Gilbert et al. [6] argued that this risk is unequal and depends on the number of air connections with China, especially with Guangdong—-the origin of the pandemic [7]. In this case, Egypt, Algeria, and South Africa were more exposed compared with Nigeria, Ethiopia, Sudan, Angola, Tanzania, Ghana, and Kenya that had moderate risk [6]. This situation caused the WHO's concern for and anticipation of rapid expansion. Nevertheless, the WHO Director General on 25 May stated, "Africa's knowledge and experience of suppressing infectious diseases have been critical to rapidly scaling up an agile response to COVID-19" [8]. This fact is supported by the number of infected and deceased in Africa, which is much lower than expected. Researchers have tried to explain the psychosocial aspect of confinement, saying that the African population has high levels of awareness about the dangers of these pandemics [9] since they have suffered from epidemics in recent years [4]. This, in turn, improved the containment procedures of African health systems, an aspect that cannot fully explain lower mortality in the country; hence, this work analyses possible molecular determinants.

\section{Main}

Previous coronaviruses (i.e. SARS-CoV and MERS-CoV) were characterized by fast and robust initial virus replication with late IFN generation, resulting in disproportionate inflammatory host response [10]. SARS-CoV-2 uses angiotensinconverting enzyme II (ACE2) and a transmembrane serine protease (TMPRSS) as cell entry receptors, followed by a cytokine-related syndrome and acute respiratory distress syndrome (ARDS), which is induced by the hyperactivation of the nuclear factor kappa B (NF-kB) most likely in nonimmune cells, including lung epithelial cells [11]. Then, SARS-CoV-2 stimulates humoral and cellular immunity systems as well as mitogen-activated protein kinase (MAPK) and nuclear NF-kB signalling pathways, which regulate inflammatory gene expression and immune cell differentiation [12]. The result is proinflammatory cytokines release [13], hyperinflammatory condition, and cytokine storm that provoke severe lung alterations $[14,15]$ and may result in multi-organ failure in COVID-19 [16].

The Janus kinase signal transducer and activator of transcription JAK/STAT pathway is the principal signalling mechanism for a wide array of cytokines and growth factors. All cytokines need JAK signalling to exert their functions [17]. JAK activation stimulates cell proliferation, differentiation, migration, and apoptosis [18]. JAK/STAT-mediated NF-kB activation by coronaviruses (i.e. SAS-CoV or MERS) is responsible for mediating the production of pro-inflammatory cytokines and chemokines. Therefore, NF-kB plays a key role in the pathogenesis of coronaviruses [19-21]. It has been observed that tyrosine kinase activity is increased in COVID-19 [22], which leads to phospholipase C (PLC) activation that actives protein kinase C (PKC). This induces reactive oxygen species (ROS) increase, ROS-mediated NF-kappa B (NF-kB) activation, and mTOR inhibition, which result in the transcriptional activation of NF-kB target genes. These genes include anti-apoptotic and survival factors, positive cell-cycle regulators, and pro-inflammatory genes, leading to cytokine production, which in turn increases autophagy $[23,24]$ and facilitates viral replication and cytokine storm. 
A study of host responsive genes (HRG) for SARS-CoV-2 showed that they are especially enriched in IL-17 signalling, cytokine-cytokine receptor interaction, and NF-kB pathways, among other proceses [25]. Research has indicated that the NF-kB pathway, which is induced by several mediators, plays a role in cytokine storm [26]. IL-6 also has a pivotal role in cytokine storm because it activates the JAK/STAT signalling pathway [27-29]. Elevated serum levels of IL-6 are commonly reported in patients with severe COVID-19 and correlate significantly with nonsurvivors [30,31]. Overall, NK-kB, JAK/STAT, and MAPK pathways are critical in COVID-19 pathogenesis.

In the following sections, the role of malaria, NF-kB, and MAPK pathways, expression of caspase-12, higher levels of LAIR-1-containing antibodies, and differential glycophorins (GYPA/B) expression in COVID-19 are discussed.

\section{Malaria}

The malaria parasite Plasmodium falciparum kills on the order of a million African children each year [32], and this is a small fraction of the number of infected individuals in the population [32-34]. In communities where everyone is repeatedly infected with Plasmodium falciparum, host genetic factors account for around $25 \%$ of the risk of severe malaria, which is a life-threatening form of the disease [34].

Sporozoites of malaria parasites ensure the endurance of their host cell by preventing apoptosis and inflammation by interfering with the host cell NF-kB pathway $[35,36]$ and hence several genes involved in the inflammatory response [36]. The parasite also inhibits STAT3, which activates a wide variety of genes that control cell proliferation and survival and whose absence inhibits the acute phase response associated with infections [37]. Angiotensin-converting enzyme 2, a SARS-CoV-2 receptor, is upregulated by IL-6 through STAT3 signalling [38]. IL-6, which is crucial for cytokine storm development, is also downregulated by the parasite [39]. Both exoerythrocytic forms (EEFs) and erythrocytic stages of malaria use the same strategies to ensure parasite expansion [36]. Other main gene upregulated by Plasmodium is TMPRSS, which encodes a serine protease needed for SARS-CoV-2 entry into the host cell [40].

Apart from these pathways, the parasite promotes PD-1 expression in T cells with cell-extrinsic immunosuppressive functions. Programmed cell death protein 1 (PD-1) is a protein on the surface of cells expressed on activated T cells, B cells, and monocytes that regulates the immune response promoting self-tolerance, suppressing $T$ cell inflammatory activity and likely regulating these cell types [41]. Overexpression of PD1 on T cells is one of the indicators of T cell exhaustion (e.g. in chronic infection) [42]. PD-1 reduces PKC/NF-kB signalling and IL-2 production and induces the expression of ubiquitin ligase E3 that leads to NF-kB degradation and T cell receptor (TCR) internalization [43]. This down-regulation of the immune response may be an essential mechanism that controls $T$ cell responses and might limit severe inflammation in patients with malaria and potentially other acute infections, such as COVID-19. It is though SARSCoV-2 increases PD-1 expression [44].

\section{Caspase-12}

Inflammasomes are large macromolecular complexes involved in inflammatory response regulation. They are key signalling platforms that detect pathogenic microorganisms and sterile stressors and activate the highly pro-inflammatory cytokines interleukin-1 $\beta$ (IL-1 $\beta$ ) and IL-18 $[45,46]$. They trigger inflammation by activating, on the one hand, caspase-1 and 
other caspases that cleave pro-IL-1 $\beta$ and pro-IL-18 into their mature active forms, and on the other hand, NF-kB pathway [46] that results in pro-inflammatory cytokines release [13]. Caspase-12 is a second member of the caspase-1 subfamily that is catalytically inactive in humans; it acts as an inhibitor of both inflammasome and NF-kB pathways [46]. Expression of human caspase-12 is predominantly confined to African descent (Figure 1) and is associated with dampened proinflammatory cytokine production and sepsis-related mortality [47]. Labbé et al. elegantly showed the role of caspase-12 in suppressing inflammatory response to malaria. Caspase-12 limited the immune control of parasite replication and dampened hyperinflammation. Experiments revealed that caspase-12 deficiency causes hyperactivation of NF-kB and enhances IFN-gamma production. As regards mechanism, caspase-12 competes with the NF-kB essential modulator (NEMO) for association with the inhibitor-kB (IkB) kinase (IKK)- $\alpha / \beta$, effectively preventing the formation of the IKK complex and inhibiting downstream transcriptional activation by NF-kB [46].

\section{Leukocyte-associated immunoglobulin-like receptor-1}

Leukocyte-associated immunoglobulin-like receptor-1 (LAIR-1) is a member of the immunoglobulin superfamily [48] that inhibits T cell activation [49]. LAIR-1 is expressed on lymphoid and myeloid cells, monocytes, and immature CD34+ progenitor cells [50]. It is also described in alveolar macrophages [51]. LAIR-1 suppresses neutrophil tissue migration and acts as a negative regulator of neutrophil-driven airway inflammation in lung diseases, such as bronchiolitis in respiratory syncytial virus (RSV) [52]. Qin et al. collected blood neutrophil gauge test data of 2976 patients who have been diagnosed with SARS-CoV-2 at Wuhan Huoshenshan Hospital in Wuhan, China. They found that disease deterioration is related to the increase in the abundance and proportion of neutrophils. The percentage of neutrophils and the absolute value of neutrophils in patients with critical illness and death were always higher than those of non-critically ill patients and surviving patients. This indicates that continued excessive activation of neutrophils plays a crucial role in SARS-CoV-2, leading to severe illness and death [25].

Likewise, COVID-19 patients who have died had a significantly higher neutrophil to lymphocyte ratio (NLR). NLR was thus positively correlated with death [53].

Achieng et al. discovered that low transcript expression of $L A I R-1$ is associated with enhanced susceptibility to malaria anaemia and severity. Blockade of the LAIR-1 inhibitory signal by Plasmodium was also associated with enhanced NF-kB activation and cytokine production [54]. The p65 subunit of NF-kB, constitutively expressed in the nucleus of immune system cells, is retained in the cytoplasm (i.e. inactive form) upon engagement of LAIR-1. This was already evident eight hours after LAIR-1 occupancy. Moreover, a reduction in IkB $\alpha$ phosphorylation, the active form of the NF-kB inhibitor, was observed after LAIR-1 engagement [55].

LAIR-1 activation decreases the boosting levels of critical components of the canonical T cell signalling pathway, including the three MAP kinases ERK1/2, JNK1/2, and p38. All three activate IL-2 gene and promote cellular proliferation [56,57], affecting cell development and inflammatory cascades by intervening with the PI3K-AKT pathway. LAIR-1 also inhibits the production of IFN-1 [58].

Activation and increased levels of NK cells have been shown in COVID-19 [59]. 
LAIR-1 in NK cells delivers a potent inhibitory signal that is capable of inhibiting target cell lysis by resting and activating NK cells [60]. In primary B cells, LAIR-1 leads to decreased cytokine production [61].

Finally, LAIR-1 suppresses cell growth by inhibiting the PI3K-AKT-mTOR axis. LAIR-1 is also involved in mRNA processing through its interaction with several eukaryotic translation initiation factors (i.e. elF4E1B, elF2S3, elF3D, elF4G2, eIF5B) and eukaryotic translation elongation factors (i.e. eEF1A2 and eEF1B2). The mechanisms involved may include LAIR-1 regulation of protein synthesis at the translational level or its action as a modulator that suppresses the PI3K-AKT-mTOR pathway directly [62].

Pieper et al. [63] reported that up to $10 \%$ of people living in malaria endemic regions produce antibodies that contain LAIR-1, suggesting a public antibody response. However, less than $1 \%$ of European individuals these antibodies (figure 2). High levels of LAIR-1-containing antibodies dominate the response to infection without conferring enhanced protection against febrile malaria. Although LAIR-1 prevalence observed in African individuals may have been promoted by malaria infection, the data suggests that it is the exposure to the malaria parasite that selects the rare LAIR-1 B cells [63].

\section{Glycophorins}

Glycophorin A and glycophorin B are red blood cell surface proteins; they are both receptors for the parasitePlasmodium falciparum, which is the principal cause of malaria in sub-Saharan Africa [64]. DUP4 is a complex structural genomic variant that carries extra copies of a glycophorin A-glycophorin B fusion gene [65] and reduces the risk of severe malaria by up to $40 \%$. DUP4 is common in Kenyan populations, with allele frequency reaching $10 \%$ [66]. DUP4 variant reaches a frequency of $13 \%$ in south-eastern African populations and is restricted to East African populations [65]. This variant that reduces the risk of severe malaria by $40 \%$ has recently increased in frequency in parts of Kenya, yet it appears to be absent in West Africa [67].

GYPA/B are involved in viral entry into the host cell and leukocyte migration, according to the GeneCards database [68]. They are receptors of several viruses for host invasion. It has been reported that several viruses bind to glycophorin proteins for penetration into the cell, including influenza virus, hepatitis A virus, rotavirus, parvovirus, Sendai virus, reovirus, and encephalomyocarditis (EMC) virus [68-70]. According to The Human Protein Atlas, GYPA/B are mainly expressed in bone marrow, erythrocytes, neutrophils, lungs, lymphoid tissues, B- and T-lymphocytes, monocytes, spleen, and kidneys. As such, malaria might protect patients against SARS-CoV-2 infection by damping regular virus-host recognition through GYPA/B.

\section{Conclusions}

Multiple genetic and immunologic factors may be involved in the severity of COVID-19 in African individuals compared with the rest of the global population. These factors include direct actions of Plasmodium falciparum in the pathogenesis, expression of caspase-12, higher levels of LAIR-1-containing antibodies, and differential glycophorins expression. Other hypotheses can be added to this, such as chloroquine and its derivative drugs used for malaria, precarious data collection, ACE2 polymorphisms and other genes, and so on. 
Knowledge of these pathophysiological mechanisms can help identify target points for drugs and vaccines development against COVID-19.

To our knowledge, this is the first study exploring the link between these variables and proposing a biological and molecular answer to the epidemiologic discrepancy in COVID-19 in Africa.

\section{References}

[1] Wang C, Horby PW, Hayden FG, Gao GF. A novel coronavirus outbreak of global health concern. Lancet 2020;395:470-3. https://doi.org/10.1016/S0140-6736(20)30185-9.

[2] Rokni M, Ghasemi V, Tavakoli Z. Immune responses and pathogenesis of SARS-CoV-2 during an outbreak in Iran: Comparison with SARS and MERS. Rev Med Virol 2020;30. https://doi.org/10.1002/rmv.2107.

[3] Uyoga S, Adetifa IMO, Karanja HK, Nyagwange J, Tuju J, Wanjiku P, et al. Seroprevalence of anti-SARS-CoV-2 IgG antibodies in Kenyan blood donors. MedRxiv 2020.

[4] Nkengasong JN, Mankoula W. Looming threat of COVID-19 infection in Africa: act collectively, and fast. Lancet 2020;395:841-2. https://doi.org/10.1016/S0140-6736(20)30464-5.

[5] Velavan TP, Meyer CG. The COVID-19 epidemic. Trop Med Int Heal 2020;25:278-80. https://doi.org/10.1111/tmi.13383.

[6] Gilbert M, Pullano G, Pinotti F, Valdano E, Poletto C, Boëlle PY, et al. Preparedness and vulnerability of African countries against importations of COVID-19: a modelling study. Lancet 2020;395:871-7. https://doi.org/10.1016/S01406736(20)30411-6.

[7] Shereen MA, Khan S, Kazmi A, Bashir N, Siddique R. COVID-19 infection: Origin, transmission, and characteristics of human coronaviruses. J Adv Res 2020;24:91-8. https://doi.org/10.1016/j.jare.2020.03.005.

[8] WHO. Opening remarks at the media briefing on COVID-19. 2020.

[9] El-Sadr WM, Justman J. Africa in the path of Covid-19. N Engl J Med 2020;383:e11. https://doi.org/10.1056/NEJMp2008193.

[10] Allegra A, Di Gioacchino M, Tonacci A, Musolino C, Gangemi S. Immunopathology of SARS-CoV-2 infection: Immune cells and mediators, prognostic factors, and immune-therapeutic implications. Int J Mol Sci 2020;21:1-19. https://doi.org/10.3390/ijms21134782.

[11] Hirano T, Murakami M. COVID-19: A New Virus, but a Familiar Receptor and Cytokine Release Syndrome. Immunity 2020;52:731-3. https://doi.org/10.1016/j.immuni.2020.04.003. 
[12] Wu D, Yang XO. TH17 responses in cytokine storm of COVID-19: An emerging target of JAK2 inhibitor Fedratinib. J Microbiol Immunol Infect 2020;53:368-70. https://doi.org/10.1016/j.jmii.2020.03.005.

[13] Li G, Fan Y, Lai Y, Han T, Li Z, Zhou P, et al. Coronavirus infections and immune responses. J Med Virol $2020 ; 92: 424-32$

[14] Kindler E, Thiel V. SARS-CoV and IFN: Too Little, Too Late. Cell Host Microbe 2016;19:139-41. https://doi.org/10.1016/j.chom.2016.01.012.

[15] Channappanavar R, Fehr AR, Vijay R, Mack M, Zhao J, Meyerholz DK, et al. Dysregulated Type I Interferon and Inflammatory Monocyte-Macrophage Responses Cause Lethal Pneumonia in SARS-CoV-Infected Mice. Cell Host Microbe 2016;19:181-93. https://doi.org/10.1016/j.chom.2016.01.007.

[16] Jafarzadeh A, Chauhan P, Saha B, Jafarzadeh S, Nemati M. Contribution of monocytes and macrophages to the local tissue inflammation and cytokine storm in COVID-19: Lessons from SARS and MERS, and potential therapeutic interventions. Life Sci 2020;257. https://doi.org/10.1016/j.Ifs.2020.118102.

[17] Dennis EA. Handbook of Cell Signaling. vol. 1-3. Elsevier Inc.; 2003. https://doi.org/10.1016/B978-0-12-1245467.X5358-3.

[18] Rawlings JS, Rosler KM, Harrison DA. The JAK/STAT signaling pathway. J Cell Sci 2004;117:1281-3.

[19] DeDiego ML, Nieto-Torres JL, Regla-Nava JA, Jimenez-Guardeno JM, Fernandez-Delgado R, Fett C, et al. Inhibition of NF- B-Mediated Inflammation in Severe Acute Respiratory Syndrome Coronavirus-Infected Mice Increases Survival. J Virol 2014;88:913-24. https://doi.org/10.1128/jvi.02576-13.

[20] Kanzawa N, Nishigaki K, Hayashi T, Ishii Y, Furukawa S, Niiro A, et al. Augmentation of chemokine production by severe acute respiratory syndrome coronavirus $3 \mathrm{a} / \mathrm{X} 1$ and $7 \mathrm{a} / \mathrm{X} 4$ proteins through NF-kB activation. FEBS Lett 2006;580:6807-12. https://doi.org/10.1016/j.febslet.2006.11.046.

[21] Yang CW, Lee YZ, Hsu HY, Shih C, Chao YS, Chang HY, et al. Targeting Coronaviral Replication and Cellular JAK2 Mediated Dominant NF-kB Activation for Comprehensive and Ultimate Inhibition of Coronaviral Activity. Sci Rep 2017;7. https://doi.org/10.1038/s41598-017-04203-9.

[22] McGee MC, August A, Huang W. BTK/ITK dual inhibitors: Modulating immunopathology and lymphopenia for COVID-19 therapy. J Leukoc Biol 2020. https://doi.org/10.1002/JLB.5COVR0620-306R.

[23] Volpe CMO, Villar-Delfino PH, Dos Anjos PMF, Nogueira-Machado JA. Cellular death, reactive oxygen species (ROS) and diabetic complications review-Article. Cell Death Dis 2018;9. https://doi.org/10.1038/s41419-017-0135-z.

[24] Jost PJ, Ruland J. Aberrant NF-kB signaling in lymphoma: Mechanisms, consequences, and therapeutic implications. Blood 2007;109:2700-7. https://doi.org/10.1182/blood-2006-07-025809. 
[25] Qin S, Xia X, Shi X, Ji X, Ma F, Chen L. Mechanistic insights into SARS-CoV-2 epidemic via revealing the features of SARS-CoV-2 coding proteins and host responses upon its infection. Bioinformatics 2020.

https://doi.org/10.1093/bioinformatics/btaa725.

[26] Mozafari N, Azadi S, Mehdi-Alamdarlou S, Ashrafi H, Azadi A. Inflammation: A bridge between diabetes and COVID-19, and possible management with sitagliptin. Med Hypotheses 2020;143.

https://doi.org/10.1016/j.mehy.2020.110111.

[27] Luo W, Li YX, Jiang LJ, Chen Q, Wang T, Ye DW. Targeting JAK-STAT Signaling to Control Cytokine Release Syndrome in COVID-19. Trends Pharmacol Sci 2020;41:531-43. https://doi.org/10.1016/j.tips.2020.06.007.

[28] Kang S, Tanaka T, Narazaki M, Kishimoto T. Targeting Interleukin-6 Signaling in Clinic. Immunity 2019;50:1007-23. https://doi.org/10.1016/j.immuni.2019.03.026.

[29] Garbers C, Heink S, Korn T, Rose-John S. Interleukin-6: Designing specific therapeutics for a complex cytokine. Nat Rev Drug Discov 2018;17:395-412. https://doi.org/10.1038/nrd.2018.45.

[30] Ruan Q, Yang K, Wang W, Jiang L, Song J. Clinical predictors of mortality due to COVID-19 based on an analysis of data of 150 patients from Wuhan, China. Intensive Care Med 2020;46:846-8. https://doi.org/10.1007/s00134-02005991-x.

[31] Giamarellos-Bourboulis EJ, Netea MG, Rovina N, Akinosoglou K, Antoniadou A, Antonakos N, et al. Complex Immune Dysregulation in COVID-19 Patients with Severe Respiratory Failure. Cell Host Microbe 2020;27:992-1000.e3. https://doi.org/10.1016/j.chom.2020.04.009.

[32] Snow RW, Guerra CA, Noor AM, Myint HY, Hay SI. The global distribution of clinical episodes of Plasmodium falciparum malaria. Nature 2005;434:214-7.

[33] Greenwood BM, Bradley AK, Greenwood AM, Byass P, Jammeh K, Marsh K, et al. Mortality and morbidity from malaria among children in a rural area of The Gambia, West Africa. Trans R Soc Trop Med Hyg 1987;81:478-86. https://doi.org/10.1016/0035-9203(87)90170-2.

[34] Mackinnon MJ, Mwangi TW, Snow RW, Marsh K, Williams TN. Heritability of malaria in Africa. PLoS Med 2005;2:1253-9. https://doi.org/10.1371/journal.pmed.0020340.

[35] Sicard A, Semblat JP, Doerig C, Hamelin R, Moniatte M, Dorin-Semblat D, et al. Activation of a PAK-MEK signalling pathway in malaria parasite-infected erythrocytes. Cell Microbiol 2011;13:836-45. https://doi.org/10.1111/j.14625822.2011.01582.x.

[36] Singh AP, Buscaglia CA, Wang Q, Levay A, Nussenzweig DR, Walker JR, et al. Plasmodium Circumsporozoite Protein Promotes the Development of the Liver Stages of the Parasite. Cell 2007;131:492-504.

https://doi.org/10.1016/j.cell.2007.09.013. 
[37] Alonzi T, Maritano D, Gorgoni B, Rizzuto G, Libert C, Poli V. Essential Role of STAT3 in the Control of the AcutePhase Response as Revealed by Inducible Gene Activation in the Liver. Mol Cell Biol 2001;21:1621-32. https://doi.org/10.1128/mcb.21.5.1621-1632.2001.

[38] Mokuda S, Tokunaga T, Masumoto J, Sugiyama E. Angiotensin-converting enzyme 2, a SARS-CoV-2 receptor, is upregulated by interleukin-6 via STAT3 signaling in synovial tissues. J Rheumatol 2020.

[39] Pied S, Civas A, Berlot-Picard F, Renia L, Miltgen F, Gentilini M, et al. IL-6 induced by IL-1 inhibits malaria preerythrocytic stages but its secretion is down-regulated by the parasite. J Immunol 1992;148:197-201.

[40] Zupin L, Pascolo L, Zito G, Ricci G, Crovella S. SARS-CoV-2 and the next generations: which impact on reproductive tissues? J Assist Reprod Genet 2020. https://doi.org/10.1007/s10815-020-01917-0.

[41] Agata $Y$, Kawasaki A, Nishimura H, Ishida $Y$, Tsubata T, Yagita H, et al. Expression of the PD-1 antigen on the surface of stimulated mouse T and B lymphocytes. Int Immunol 1996;8:765-72. https://doi.org/10.1093/intimm/8.5.765.

[42] Pauken KE, Wherry EJ. Overcoming T cell exhaustion in infection and cancer. Trends Immunol 2015;36:265-76. https://doi.org/10.1016/j.it.2015.02.008.

[43] Karwacz K, Bricogne C, MacDonald D, Arce F, Bennett CL, Collins M, et al. PD-L1 co-stimulation contributes to ligand-induced T cell receptor down-modulation on CD8 + T cells. EMBO Mol Med 2011;3:581-92. https://doi.org/10.1002/emmm.201100165.

[44] Schön MP, Berking C, Biedermann T, Buhl T, Erpenbeck L, Eyerich K, et al. COVID-19 and immunological regulations - from basic and translational aspects to clinical implications. JDDG - J Ger Soc Dermatology 2020. https://doi.org/10.1111/ddg.14169.

[45] Latz E, Xiao TS, Stutz A. Activation and regulation of the inflammasomes. Nat Rev Immunol 2013;13:397-411. https://doi.org/10.1038/nri3452.

[46] Labbé K, Miu J, Yeretssian G, Serghides L, Tam M, Finney CA, et al. Caspase-12 Dampens the Immune Response to Malaria Independently of the Inflammasome by Targeting NF-KB Signaling. J Immunol 2010;185:5495-502. https://doi.org/10.4049/jimmunol.1002517.

[47] Saleh M, Vaillancourt JP, Graham RK, Huyck M, Srinivasula SM, Alnemri ES, et al. Differential modulation of endotoxin responsiveness by human caspase-12 polymorphisms. Nature 2004;429:75-9. https://doi.org/10.1038/nature02451.

[48] Meyaard L, Adema GJ, Chang C, Woollatt E, Sutherland GR, Lanier LL, et al. LAIR-1, a novel inhibitory receptor expressed on human mononuclear leukocytes. Immunity 1997;7:283-90. https://doi.org/10.1016/S1074-7613(00)80530-0.

[49] Ravetch J V., Lanier LL. Immune inhibitory receptors. Science (80- ) 2000;290:84-9. https://doi.org/10.1126/science.290.5489.84. 
[50] Hammad R, Hamdino M, El-Nasser AM, Sobhy A, Eldesoky NAR, Mashaal AM, et al. Immunoregulatory complement receptor-1 and leukocyte-associated Ig-like receptor-1 expression on leukocytes in Psoriasis vulgaris. Innate Immun 2020. https://doi.org/10.1177/1753425920942570.

[51] Houben ML, Nordkamp MJMO, Nikkels PGJ, Ent CKV Der, Meyaard L, Bont L. Soluble leukocyte-associated ig-like receptor-1 in amniotic fluid is of fetal origin and positively associates with lung compliance. PLoS One 2013;8. https://doi.org/10.1371/journal.pone.0083920.

[52] Kumawat K, Geerdink RJ, Hennus MP, Roda MA, Van Ark I, Leusink-Muis T, et al. LAIR-1 limits neutrophilic airway inflammation. Front Immunol 2019;10. https://doi.org/10.3389/fimmu.2019.00842.

[53] Pakos I, Lo KB, Salacup G, Pelayo J, Bhargav R, Peterson E, et al. Characteristics of peripheral blood differential counts in hospitalized patients with COVID-19. Eur J Haematol 2020:ejh.13509. https://doi.org/10.1111/ejh.13509.

[54] Achieng AO, Guyah B, Cheng Q, Ong'echa JM, Ouma C, Lambert CG, et al. Molecular basis of reduced LAIR1 expression in childhood severe malarial anaemia: Implications for leukocyte inhibitory signalling. EBioMedicine 2019;45:278-89. https://doi.org/10.1016/j.ebiom.2019.06.040.

[55] Poggi A, Pellegatta F, Leone BE, Moretta L, Raffaella Zocchi M. Engagement of the leukocyte-associated Ig-like receptor-1 induces programmed cell death and prevents NF-kB nuclear translocation in human myeloid leukemias. Eur J Immunol 2000;30:2751-8. https://doi.org/10.1002/1521-4141(200010)30:10<2751::AID-IMMU2751>3.0.CO;2-L.

[56] Genot E, Cleverley S, Henning S, Cantrell D. Multiple p21ras effector pathways regulate nuclear factor of activated T cells. EMBO J 1996;15:3923-33.

[57] Park JE, Brand DD, Rosloniec EF, Yi AK, Stuart JM, Kang AH, et al. Leukocyte-associated immunoglobulin-like receptor 1 inhibits T-cell signaling by decreasing protein phosphorylation in the T-cell signaling pathway. J Biol Chem 2020;295:2239-47. https://doi.org/10.1074/jbc.RA119.011150.

[58] Martínez-Esparza M, Ruiz-Alcaraz AJ, Carmona-Martínez V, Fernández-Fernández MD, Antón G, Muñoz-Tornero M, et al. Expression of LAIR-1 (CD305) on human blood monocytes as a marker of hepatic cirrhosis progression. J Immunol Res 2019;2019. https://doi.org/10.1155/2019/2974753.

[59] Masselli E, Vaccarezza M, Carubbi C, Pozzi G, Presta V, Mirandola P, et al. NK cells: A double edge sword against SARS-CoV-2. Adv Biol Regul 2020;77. https://doi.org/10.1016/j.jbior.2020.100737.

[60] Meyaard L. The inhibitory collagen receptor LAIR-1 (CD305). J Leukoc Biol 2008;83:799-803.

[61] Merlo A, Tenca C, Fais F, Battini L, Ciccone E, Grossi CE, et al. Inhibitory receptors CD85j, LAIR-1, and CD152 down-regulate immunoglobulin and cytokine production by human B lymphocytes. Clin Diagn Lab Immunol 2005;12:70512. https://doi.org/10.1128/CDLI.12.6.705-712.2005.

[62] Liu Y, Ma L, Shangguan F, Zhao X, Wang W, Gao Z, et al. LAIR-1 suppresses cell growth of ovarian cancer cell via 
the PI3K-AKT-mTOR pathway. Aging (Albany NY) 2020;12. https://doi.org/10.18632/aging.103589.

[63] Pieper K, Tan J, Piccoli L, Foglierini M, Barbieri S, Chen Y, et al. Public antibodies to malaria antigens generated by two LAIR1 insertion modalities. Nature 2017;548:597-601. https://doi.org/10.1038/nature23670.

[64] Jaskiewicz E, Jodłowska M, Kaczmarek R, Zerka A. Erythrocyte glycophorins as receptors for Plasmodium merozoites. Parasites and Vectors 2019;12. https://doi.org/10.1186/s13071-019-3575-8.

[65] Algady W, Louzada S, Carpenter D, Brajer P, Färnert A, Rooth I, et al. The Malaria-Protective Human Glycophorin Structural Variant DUP4 Shows Somatic Mosaicism and Association with Hemoglobin Levels. Am J Hum Genet 2018;103:769-76. https://doi.org/10.1016/j.ajhg.2018.10.008.

[66] Band G, Rockett KA, Spencer CCA, Kwiatkowski DP, Si Le Q, Clarke GM, et al. A novel locus of resistance to severe malaria in a region of ancient balancing selection. Nature 2015;526:253-7. https://doi.org/10.1038/nature15390.

[67] Leffler EM, Band G, Busby GBJ, Kivinen K, Le QS, Clarke GM, et al. Resistance to malaria through structural variation of red blood cell invasion receptors. Science (80- ) 2017;356:1140-52. https://doi.org/10.1126/science.aam6393.

[68] Genecards. GYPA Gene - GeneCards | GLPA Protein | GLPA Antibody. GenecardsOrg 2020.

https://www.genecards.org/cgi-bin/carddisp.pl?gene=GYPA (accessed 20 August 2020).

[69] Gekker M, Coutinho ESF, Berger W, Luz MP da, Araújo AXG de, Pagotto LFA da C, et al. Early scars are forever: Childhood abuse in patients with adult-onset PTSD is associated with increased prevalence and severity of psychiatric comorbidity. Psychiatry Res 2018;267:1-6. https://doi.org/10.1016/J.PSYCHRES.2018.05.042.

[70] Sciencedirect. Hepatitis A Virus - an overview | ScienceDirect Topics. SciencedirectCom 2020. https://www.sciencedirect.com/topics/biochemistry-genetics-and-molecular-biology/hepatitis-a-virus (accessed 21 August 2020).

\section{Declarations of interest: none}

Funding: This research did not receive any specific grant from funding agencies in the public, commercial, or not-forprofit sectors.

\begin{tabular}{|l|l|l|l|l|}
\hline DNA Source & \multicolumn{1}{|c|}{ Stop } & Stop/Arg & Arg \\
\hline & & TGA & (T/C)GA & CGA \\
\hline Caucasian & 187 & 187 & 0 & 0 \\
\hline Asian & 160 & 160 & 0 & 0 \\
\hline South African & 153 & 120 & 31 & 2 \\
\hline African American & 623 & 499 & 113 & 11 \\
\hline TOTAL & 1123 & 966 & 144 & 13 \\
\hline
\end{tabular}


Fig.1. Sequence analysis of more than 1,100 genomic DNA samples from people of distinct ethnic backgrounds showed that most encoded the truncated prodomain-only form of caspase-12 (Csp12-S). The less-frequent CGA ( $\operatorname{Arg})$ polymorphism resulting in a full-length caspase polypeptide (Csp12-L) was found only in populations of African descent and was absent in all Caucasian and Asian groups tested.

\begin{tabular}{|l|l|l|l|l|} 
& $\boldsymbol{n}$ & IgG & IgM & Monoclonal LAIR-1 \\
\hline Tanzanian & 112 & $6(5.4 \%)$ & $2-4 \%^{*}$ & $52^{*}$ \\
\hline Malian & 656 & $57(8.7 \%)$ & $2-4 \% *$ & $52^{*}$ \\
\hline European & 1043 & $3(0.28 \%)$ & $4(0.38 \%)$ & 0
\end{tabular}

Fig.2. Prevalence of LAIR-1-containing antibodies in South-eastern African versus Europe.

* Sources together 